\title{
New Allopathic Medical Schools and Family Physicians
}

Joanna Drowos, DO, MPH, MBA

(J Am Board Fam Med 2019;32:651-652.)

In 2018 the 8 national family medicine organizations set a goal of having $25 \%$ of graduating US medical students choose family medicine as their specialty by $2030(25 \times 2030$ campaign $) .{ }^{1}$ If current trends continue, this goal will not be met, as only $9.3 \%$ of graduating allopathic medical students selected family medicine residencies in $2018 .^{2}$ The projected shortage of future primary care physicians has increased the urgency to ensure an adequate number of graduates from US medical schools enter family medicine each year. Developing expanded class sizes and opening new allopathic medical schools are strategies aimed at alleviating the impending primary care shortage. ${ }^{3}$

"New Allopathic Medical Schools Train Fewer Family Physicians than Older Ones"4 discusses the contributions newly accredited allopathic medical schools are making to graduating future family medicine specialists. In this report, analysis of data from the 2018 American Medical Association Masterfile reveals that graduates of the new allopathic medical schools were nearly $40 \%$ less likely than their colleagues at established medical schools to select family medicine training programs. Identifying this disparity is the first step in understanding specialty selection trends, and providing guidance to new and existing medical schools on strategies to promote graduates choosing family medicine residencies.

Funding: Dr. Drowos serves as the Associate Dean for Faculty Affairs and the Clerkship Director for Community and Preventive Medicine at the Charles E. Schmidt College of Medicine at Florida Atlantic University.

Conflict of interest: none declared.

Corresponding author: Joanna Drowos, DO, MPH, MBA, Department of Integrated Medical Science, Florida Atlantic University, 777 Glades Road, Building 71, Room 215, Boca Raton, FL 33431. (E-mail: jdrowos@health.fau.edu).
According to medical students pursuing family medicine training, specialty choice is heavily influenced by interest in family medicine before entering medical school, leadership opportunities in the field, involvement in student interest groups, and mentoring by faculty within and beyond the specialty. ${ }^{5}$ Family-medicine educators should consider their own engagement in mentoring students, as well as seek out additional allies from other specialties who will support students pursuing the specialty. A complex mix of life experiences before matriculating, combined with educational experiences and the learning environment encountered during medical school, ultimately shape choice of specialty. However, in another study examining the contributions of various medical schools to the total number of family medicine residency positions, there are certain "bright spots," or institutions that are graduating larger percentages of future family physicians. These tend to be public institutions, with smaller class size, and the presence of family medicine departments within the organizational structure. In reviewing the list of institutions identified in that particular study, some are newer schools, suggesting there is variability in the ability of newer schools to promote family medicine. ${ }^{6}$ Family medicine educational leaders need to consider why these particular schools are successful at recruiting medical students to family medicine, and should encourage implementing changes in order encourage the development of future family physicians at all medical schools.

Additional strategies identified in the literature as supporting graduates selecting family medicine, include admission practices that promote acceptance of racially and ethnically diverse studentsincluding those from lower-income families, as well as pipeline programs for students with stated inter- 
est in family medicine. ${ }^{7}$ Engaging in innovative curricula with a primary care focus, as well as involvement of family medicine faculty across the curriculum, promote the specialty to graduating students. Exposure to family medicine residents, mentoring from faculty, and required clinical experiences in family medicine-such as clerkships, have all encouraged the choice of family medicine. ${ }^{7}$ Medical schools that value family medicine, offer strong leadership and mentoring within the specialty, and prioritize educational opportunities to engage students in the field, can ultimately generate interest in the specialty and ensure the adequacy of our future primary care workforce.

My experience building a new medical school has been consistent with the authors' findings, in terms of the low rates of students selecting family medicine programs. We are a community-based school, housing faculty in 1 integrated clinical department. While we do have a mandatory longitudinal primary care clerkship, the practice climate within our community lacks support for physicians to practice full-spectrum family medicine. This study has inspired me to think about additional strategies to promote family medicine as a specialty and to highlight the contributions our new medical school will make to the future physician workforce.

This article raises the important question as to whether expansion of allopathic medical schools is sufficiently meeting the goal of expanding the primary care workforce. Newer and existing institutions should consider their formal structure in promoting family medicine to students, as well as the nature of the learning environment, questioning whether they can take additional steps to promote family medicine as a future specialty. Continuing to document trends in the types of medical schools contributing to the future workforce and looking at the particular institutions that have been successful in promoting family medicine can guide newer and existing allopathic medical schools to better meet the $25 \times 2030$ goal.

To see this article online, please go to: bttp://jabfm.org/content/ 32/5/651.full.

\section{References}

1. Family Medicine For America's Health. September 2018 Update. Available from: https://fmahealth.org/ september-2018-monthly-update/. Accessed June 15, 2019.

2. National Resident Matching Program. Results and Data: 2018 Main Residency Match. Available from: https://mk0nrmpcikgb8jxyd19h.kinstacdn.com/ wpcontent/uploads/2018/04/Main-Match-ResultandData-2018.pdf. Accessed June 15, 2019.

3. Shipman SA, Jones KC, Erikson CE, Sandberg SF. Exploring the workforce implications of a decade of medical school expansion: variations in medical school growth and changes in student characteristics and career plans. Acad Med 2013;88:1904-12.

4. Beachler B, Jabbarpour Y, Kamerow DB, et al. New allopathic medical schools train fewer family physicians than older ones. J Am Board Fam Med 2019;32: 653-654.

5. Kost A, Bentley A, Phillips J, Kelly C, Prunuske J, Morley CP. Graduating medical student perspectives on factors influencing specialty choice: an AAFP National Survey. Fam Med 2019;51:129-36.

6. Phillips JP, Wendling A, Bentley A, Marsee R, Morley CP. Trends in US medical school contributions to the family physician workforce: 2018 update from the American Academy of Family Physicians. Fam Med 2019;51:241-50.

7. Senf JH, Campos-Outcalt D, Kutob R. Factors related to the choice of family medicine: a reassessment and literature review. J Am Board Fam Pract 2003;16: 502-12. 